\begin{tabular}{|l|l|l|l|l|l|}
\hline J. Tek. Ling & Vol.11 & No.2 & Hal. 265 - 270 & Jakarta, Mei 2010 & ISSN 1441-318X \\
\hline
\end{tabular}

\title{
KERAGAMAN LUMUT DAUN DI HUTAN BEKAS TERBAKAR BUKIT BANGKIRAI, KALIMANTAN TIMUR. MOSS DIVERSITY IN THE FOREST FIRE FROM BUKIT BANGKIRAI, EAST KALIMANTAN
}

\author{
Florentina Indah Windadri' ${ }^{1}$, Ida Haerida ${ }^{1)}$ Tomio YAMAGUCHI') \\ dan Hideyuki Shimizu ${ }^{3)}$ \\ Peneliti di Pusat Penelitian Biologi, CSC_LIPI ${ }^{11}$ \\ Hiroshima University, Hiroshima-Japan ${ }^{2)}$ \\ National Institute for Environmental Studies, Tsukuba-Japan ${ }^{3)}$
}

\begin{abstract}
Bukit Bangkirai is a public recreation forest in East Kalimantan. During the long dry season in 1982-1983 and 1997-1998 some parts of the forest have burnt out, only small part war escaped. Bryophytes are small plant and usually abundantly grows on the forest. The Bryodiversity research in the Bukit Bangkirai has been done in the 2000 to 2003. Total sample of bryophyte collections about 3000 numbers since seven period collections and the result of identification were found 92 species including 27 genera and 9 families. The dominant mosses found are Achantorrhynchium papilatum, Arthrocormus schimperi, Leucobryum sanctum, Octoblepharum albidum, Pyrrhobryum spiniforme, Syrrhopodon albovaginatus and Syrrhopodon spiculosus. Only four species found in control plot. They are Ctenidium malacobolum, Fissidens zippleianus, Groutiella tomentosa and Taxithellium lindbergii. Acroporium diminutum, Leucobryum juniperinoides, Calymperes aeruginosum, Fissidens robinsonii and Syrrhopodon semilimber were only found in the light damage plot and Fissidens wichurae, Isopterygium textori, Leucobryum bowringii, Syrrhopodon confertus were only found in the heavy damage plot. The mosses usually grows on the soil and rotten logs in damp site.
\end{abstract}

Key words: Bangkirai forest recreation, east Kalimantan, mosses, burn areas, diversity.

\section{PENDAHULUAN}

Indonesia disebut sebagai satu negara megabiodiversiti karena kekayaan alamnya yang sangat melimpah. Namun kekayaan alam tersebut telah mengalami penurunan dari tahun ketahun akibat adanya penggundulan hutan. Demikian pula dengan kebakaran hutan yang sering terjadi di Kalimantan. Kebakaran hutan ini antara lain disebabkan oleh terbakarnya lapisan batu bara di bawah lapisan tanah akibat panas terik yang terjadi terus menerus selama musim kemarau. Oleh karena itu di dalam hutan bekas terbakar akan terjadi perubahan lingkungan bahkan perubahan ekosistem khususnya bagi pertumbuhan lumut. Faktor lingkungan seperti kelembaban udara, curah hujan, dan lamanya musim kemarau merupakan parameter lingkungan 
yang penting bagi kelompok tumbuhan lumut khususnya di hutan tropis. Faktorfaktor tersebut akan sangat mempengaruhi kelimpahan dan kekayaan jenisnya ${ }^{1,2}$. Bagi lumut yang tumbuh di tanah, tipe tanah juga sangat berpengaruh. Kekayaan jenis lumut maupun populasinya di tanah podzolik lebih tinggi dibandingkan di tanah laktosol pada area yang sama. Di hutan tropis dataran rendah keanekaragaman jenis lumut hati (hepatic) lebih besar dibandingkan lumut daun (musci). Beberapa suku pada lumut yang sering ditemukan di hutan tropis antara lain Calymperaceae, Meteoriaceae, Lejeuneaceae and Radulaceae ${ }^{1)}$.

Keragaman jenis lumut di Kalimatan pernah dilaporkan sebanyak 607 jenis, 57 jenis diantaranya berasal dari Kalimantan Timur $^{3)}$. Bukit Bangkirai merupakan salah satu hutan wisata alam yang terletak di sebelah barat laut Balikpapan, Kalimatan Timur. Keadaan alamnya berupa hutan hujan tropis dataran rendah, hutan sekunder, hutan bekas HPH, dan area pertanian. Sebagian besar hutannya pernah mengalami kebakaran pada saat musim kering yang panjang tahun 1982, 1983, 1997, dan tahun 1998. Kawasan hutan ini didominasi oleh pohon bangkirai (Shorea laevis) dan telah dikonservasi sebagai taman hutan wisata alam dengan nama Bukit Bangkirai. Di dalam kawasan hutan yang pernah mengalami kebakaran telah terjadi perubahan ekosistem. Adanya perubahan ekosistem akan berpengaruh pada keanekaragaman jenis biotanya. Untuk mengetahui keragaman biota pasca perubahan ekosistem perlu dilakukan penelitiannya.

Kawasan hutan wisata alam Bukit Bangkirai merupakan pilihan dalam penelitian ini karena sebagian besar hutannya telah terbakar, dan belum pernah dilakukan penelitian khususnya keanekaragaman jenis lumut daun atau musci pasca kebakaran. Disamping itu dipilinnya lumut daun sebagai topik dalam penelitian ini karena dilaporkan bahwa lumut dapat menaikkan formasi tanah dengan mempercepat kerusakan batuan secara fisik maupun kimia yang diakibatkan oleh cuaca (hujan\& angin), mampu menangkap material organik maupun anorganik dan menambahkan secara langsung material yang belum terdekomposisi ${ }^{2}$.

\section{METODOLOGI}

\subsection{Lokasi dan waktu penelitian.}

Lokasi penelitian berada di kawasan hutan wisata alam Bukit Bangkirai dan sekitarnya di bawah pengelolaan PT PERHUTANI I. Secara geografis kawasan ini berada di antara Gunung Mentawir dan Batuampar, berketinggian sekitar $110 \mathrm{~m}$ di atas permukaan laut, terletak pada posisi koordinat $0^{\circ} 58^{\prime}-0^{\circ} 05^{\prime} \mathrm{LS}$ dan $16^{\circ} 47^{\prime}-16^{\circ} 57^{\prime} B T$. Kondisi lokasi penelitian berbukit-bukit dengan beberapa aliran sungai di bagian lembahnya.Penelitian dilakukan pada pertengahan tahun 2000 hingga awal 2003. Pada tahap awal dilakukan koleksi lumut secara umum dan dilanjutkan pendataan keragaman jenisnya di petak observasi (petak permanent penelitian ekologi). Penelitian dilakukan dua kali setiap tahunnya yaitu pada musim penghujan (Oktober-November) dan musim kemarau (Februari-Maret).

\subsection{Koleksi}

Koleksi lumut daun secara umum dilakukan untuk mengetahui keanekaragaman lumut di lokasi penelitian dengan menjelajahi seluruh area hutan yang terbakar maupun tidak terbakar di hutan wisata alam Bukit Bangkirai. Dalam pengambilan sample lumut digunakan metode Cornard ${ }^{4}$ yaitu mengambil contoh lumut yang ditemukan di lokasi penelitian secara lengkap (terdapat generasi gametofit dan sporofit) serta mencatat data-data lain yang diperlukan. Data-data tersebut antara lain habitat, substrat, dan warna.Spesimen dimasukkan dalam amplop yang dapat menyerap air, kemudian dikering anginkan. 


\subsection{Pendataan}

Pendataan lumut pada petak observasi dilakukan di sub-sub petak terseleksi yaitu di petak Kontrol $(\mathrm{K})$, terbakar ringan (Lightly Damage / LD), dan petak terbakar berat (Hardly Damage / HD) dengan ukuran 10m x 10m. Jumlah subpetak untuk setiap petak beragam. Pada petak kontrol observasi dilakukan secara sistematis di 19 sub petak, karena persebaran lumut di petak ini merata sedangkan di petak terbakar ringan dan berat pertumbuhan lumut tidak merata sehingga jumlah subpetak yang berbeda yaitu 16 subpetak untuk hutan terbakar ringan dan 17 petak untuk hutan terbakar berat (gambar 1). Semua lumut yang tumbuh di tanah, kayu lapuk, kayu mati, pangkal pohon dan daun dicatat dan diambil contohnya untuk keperluan identifikasi.

\subsection{Identifikasi}

Identifikasi lumut dilakukan di Herbarium Bogoriense, Cibinong dan di Hiroshima University, Hiroshima, Jepang. Beberapa pustaka acuan yang digunakan dalam identifikasi antara lain : 'A Handbook of Malesian Mosses, volume 1-3'5,6,7), 'Mosses of The Philippines'8), 'Mosses and Liverworts of Hong Kong, volume 1'9), 'The moss family Calymperaceae (Musci) in the Phillipines'10), 'The mosses reported from Borneo'3). Spesimen yang telah teridentifikasi kemudian diproses dan disimpan sebagai koleksi di Herbarium Bogoriense.Untuk specimen yang diidentifikasi di Jepang maka setelah selesai identifikasi wajib dikirim kembali duplikatnya dan disimpan di Herbarium Bogoriense

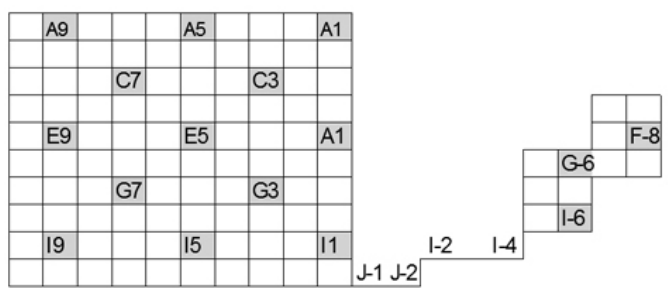

PLOT $\mathrm{K}$

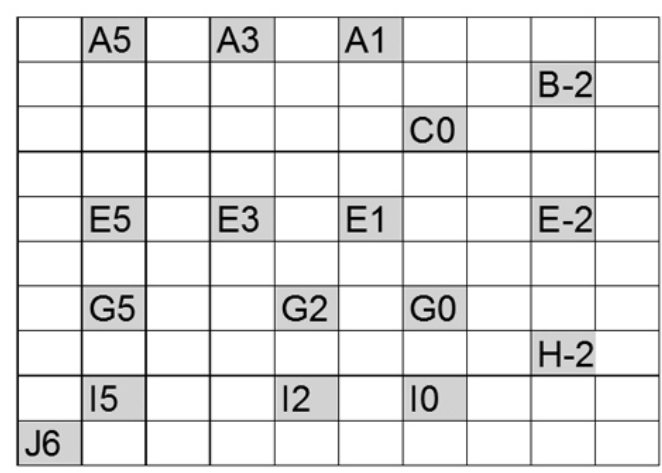

PLOT HD

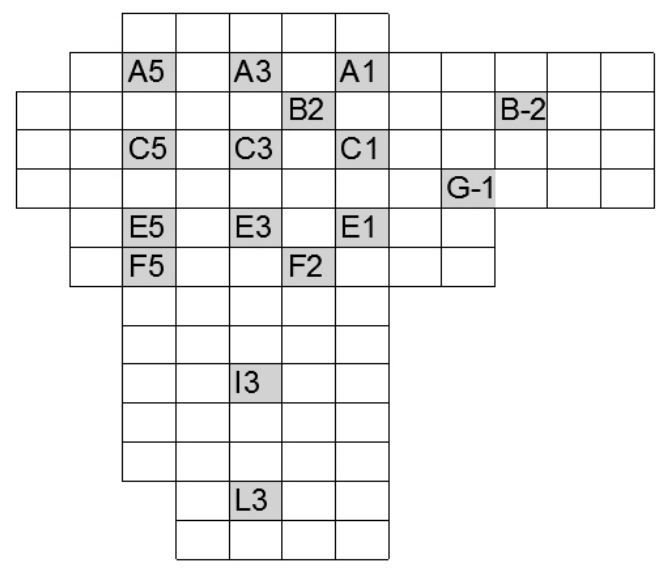

\section{PLOT LD}

Keterangan:

$\mathrm{K}$ : petak kontrol

LD : petak terbakar ringan

HD : petak terbakar berat sub petak obaservasi

\section{HASIL DAN PEMBAHASAN}

Lumut daun di kawasan hutan wisata alam Bukit Bangkirai tumbuh pada berbagai macam substrat antara lain tanah, serasah, bebatuan, batang pohon, kayu lapuk, kayu mati, pangkal pohon dan perakarannya. Lumut -lumut tersebut umumnya tumbuh tercampur antara jenis satu dengan jenis lainnya. Dari hasil koleksi di petak permanen hutan wisata alam Bukit Bangkirai dan sekitarnya tercatat 3000 nomor koleksi dan telah teridentifikasi menjadi 92 jenis, tergolong dalam 27 marga 
dan 9 suku (table 1). Jenis-jenis yang dominan antara lain Achantorrhynchium papilatum, Arthrocormus schimperi, Leucobryum sanctum, Octoblepharum albidum, Pyrrhobryum spiniforme, Syrrhopodon albovaginatus dan Syrrhopodon spiculosus.

Petak kontrol (plot K) merupakan area hutan primer yang tidak terbakar. Di dalam petak ini sebagian besar pohon tumbuh tinggi dengan kanopi cukup rapat sehingga membuat lingkungan sekitarnya teduh dan lembab, tidak ditemukan semak-semak di lantai hutannya. Lumut umumnya tumbuh di tanah, pangkal pohon, kayu lapuk dan batang pohon. Sebelas jenis dari 51 jenis lumut yang dikoleksi di petak ini tidak ditemukan di petak lainnya. Jenis-jenis tersebut adalah Calymperes afzeli, Calymperes erosum, Leucophanes massartii, Mitthyridium wallisi, Ctenidium malacobolum, Pseudotaxiphyllum pohliaecarpum, Leucobryum aduncum var. scalare, Groutiella tomemtosa, Taxithelium kerianum, Taxithelium vermieri dan Taxithelium lindbergii.

Petak terbakar ringan (plot LD) merupakan hutan sekunder dengan beberapa pohon yang tidak terbakar tumbuh tinggi, semak dan perdu berdiameter kurang dari $30 \mathrm{~cm}$ mendominasi. Di beberapa sub petak berupa rawa. Kondisi lantai hutannya basah dan banyak ditemukan kayu mati atau kayu lapuk sebagai substrat lumut. Di batang-batang pohon sering ditemukan beberapa jenis lumut dari marga Mitthyridium dan Arthrocormus. Lumut yang ditemukan dalam petak ini berjumlah 49 jenis, 4 jenis diantaranya yaitu Mitthyridium luteum, Syrrhopodon tjibodensis, Fissidens braunii dan Acroporium convolutum tidak ditemukan dipetak kontrol maupun terbakar berat.

Petak terbakar berat (plot HD) merupakan area terbuka dan kondisi lingkungannya panas. Di lokasi ini semua pohon tinggi terbakar dan hanya tersisa tonggak-tonggak kayunya. Beberapa perdu dan anak pohon ditemukan di petak ini, sedangkan lantai hutannya di dominasi oleh paku-pakuan dari marga Nephrolepis dan Gleichenia. Suhu di petak ini lebih tinggi dibandingkan dengan petak lainnya. Lumut biasanya tumbuh di tanah, kayu-kayu lapuk atau pohon mati yang tumbang dan tertutup oleh paku-pakuan atau semak. Lumut tidak ditemukan tumbuh pada batang-batang pohon mati yang tegak, perdu maupun anak pohon. Jumlah lumut yang ditemukan 44 jenis, 5 jenis diantaranya hanya ditemukan di petak ini yaitu Fissidens wichurae, Ectropothecium ferrugineum, Isopterygium textori, Isopterygium saxense dan leucobryum bowringii.

Dari perbandingan data antara petak kontrol (plot K), terbakar ringan (plot LD) dan terbakar berat (plot HD) dapat diketahui bahwa keanekaragaman jenis dan populasi lumut di petak terbakar berat (plot HD) paling rendah. Hal ini tidak sesuai dengan laporan Richardson ${ }^{11)}$ yang menyatakan bahwa suksesi lumut daun (musci) di hutan bekas terbakar menjadi melimpah jika kolonisasi dari tumbuhan tingginya lambat. Di lokasi penelitian khususnya di petak terbakar berat (plot HD) kolonisasi tumbuhan tingginya lambat namun pertumbuhan semak dan paku-pakuannya cepat dan menutupi lantai hutannya. Keadaan seperti ini menyebabkan sinar matahari dan air hujan yang sampai ke lantai hutan sedikit. Disamping itu juga akan berdampak pada kenaikan suhu lingkungan yang diikuti dengan penguapan yang meningkat sehingga lingkungan menjadi kering dan terasa panas terik. Perkecambahan spora lumut memerlukan kelembaban yang cukup serta lingkungan yang teduh dan tidak terlalu panas. Dengan kondisi lingkungan yang demikian maka bijibiji atau spora lumut di lantai hutannya tidak dapat berkecambah sehingga akan berakibat rendahnya populasi maupun keragaman jenisnya. Hal ini sesuai dengan laporan Rhicard $^{1)}$ yang menyatakan bahwa suhu lingkungan yang tinggi tidak cocok untuk perkembangan populasi maupun keragaman jenis briofita. Meskipun demikian masih dapat ditemukan beberapa jenis lumut yang mampu tumbuh di petak ini. Jenis-jenis lumut yang ditemukan umumnya tumbuh di bawah semak-semak dan membentuk koloni atau 
bantalan yang rapat. Dengan terbentuknya koloni atau bantalan yang cukup rapat mampu menyerap dan menyimpan air hujan yang ada untuk mempertahankan kehidupannya disaat lingkungan menjadi kering. Beberapa jenis lumut di hutan bekas terbakar (plot LD \& HD) yang tumbuh membentuk koloni atau bantalan di tanah atau kayu-kayu lapuk antara lain Leucobryum chlorophyllosum dan Syrrhopodon muelleri. Leucobryum chlorophyllosum dilaporkan mempunyai substrat pertumbuhan berupa kayu mati, batang pohon atau pangkal pohon ${ }^{12)}$ sedangkan Syrrhopodon muelleri tumbuh bersubstrat batang pohon atau akar papan dengan lingkungan lembab ${ }^{6}$. Dengan ditemukannya kedua jenis ini pada substrat yang berbeda dengan laporan Eddy ${ }^{6)}$ dan Yamaguchi ${ }^{12)}$ menunjukkan adanya peluasan substrat pertumbuhan bagi kedua jenis lumut tersebut. Hal ini dimungkinkan karena tanah dan kayu lapuk merupakan dua macam substrat yang mudah menyerap air dan menyimpannya dalam waktu yang relatif lama dibandingkan dengan substrat lainnya sehingga dapat membuat lingkungan menjadi lembab. Dengan kondisi yang demikian maka spora-spora lumut yang jatuh pada kedua substrat tersebut dapat berkecambah dan tumbuh berkembang menjadi tumbuhan lumut yang baru. Dua jenis lumut lain yaitu Fissidens wichurae and Isopterygium textori hanya ditemukan di area terbakar berat (plot HD). Fissidens wichurae dilaporkan tumbuh di bebatuan di tempat yang teduh ${ }^{5)}$ sedangkan Isopterygium textori tumbuh di bebatuan yang basah ${ }^{8)}$. Kedua jenis ini di lokasi penelitian ditemukan tumbuh di tanah dengan kondisi kering dan panas. Dengan demikian menunjukkan bahwa kedua jenis lumut ini merupakan jenis yang toleran terhadap kondisi kering dan panas.

Apabila ditinjau dari keragaman jenisnya, $51 \%$ lumut yang tumbuh di petak LD dan HD mempunyai kesamaan dengan jenis- jenis di petak control (plot K) atau hutan di sekitarnya. Hal ini menunjukkan bahwa sebagian besar jenis-jenis lumut yang tumbuh di hutan bekas terbakar merupakan hasil perkecambahan spora atau kuncup lumut dari petak kontrol (plot K) atau hutan disekitarnya. Spora-spora tersebut dapat disebarkan melalui air hujan, angin atau kaki- kaki hewan. Jenis-jenis lumut yang ditemukan mendominasi lokasi penelitian tergolong dalam suku Calymperaceae. Suku ini merupakan satu kelompok lumut tropis yang tumbuh di dataran rendah dan hutan-hutan sekitar pantai ${ }^{13)}$. Substrat pertumbuhannya berupa batang pohon, batuan atau tanah ${ }^{10}$. Anggota suku ini tumbuh tegak atau menjalar, membentuk bantalan. Daunnya berdinding tebal, berkosta yang terdiri dari dua lapisan pita stereid terletak di bagian dorsal dan ventral, berfungsi sebagai penyokong sel-sel berklorofil. Adanya sifat daun demikian memungkinkan anggota kelompok lumut ini dapat menyimpan air di dalam lapisan stereidnya sebagai cadangan disaat kering, sehingga di tempat-tempat seperti hutan bekas terbakar (plot HD \& LD) masih dapat ditemukan pertumbuhan kelompok tumbuhan ini. Perkembang biakan generatif menggunakan spora yang dihasilkan oleh generasi sporofit, terletak dalam kotak spora (kapsul) yang terdapat di ujungi individunya. Selain itu juga dapat berkembang biak secara vegetatif selama mampu menghasilkan kuncupkuncup (gemma) halus di ujung daunnya. Kuncup (gemma) biasanya terbentuk untuk menyesuaikan diri pada kondisi kering dan panas ${ }^{14)}$. Dengan dimilikinya dua macam alat perkembangbiakan pada suku Calymperaceae maka dimungkinkan persebaran dan populasinya akan lebih besar dibandingkan dengan kelompok sukusuku lainnya sehingga keberadaannya akan lebih dominant. Hal ini terbukti pada hasil penelitian yang dilakukan di hutan bekas terbakar Bukit Bangkirai ini.

\section{KESIMPULAN}

Hasil identifikasi lumut dari lokasi penelitian di hutan wisata alam Bukit 
Bangkirai, Kalimantan Timur ditemukan 92 jenis lumut daun (musci) yang digolongkan dalam 27 marga dan 9 suku. Lumut- lumut yang tumbuh di hutan bekas terbakar sebagian besar berasal dari hutan di sekitarnya dan didominasi oleh suku Calymperaceae. Lumut-lumut tersebut umumnya tumbuh membentuk bantalan yang rapat sehingga dapat menyerap air lebih banyak serta menyimpannya sebagai cadangan di musim kemarau (kering).

\section{UCAPAN TERIMA KASIH}

Penulis mengucapkan terimakasih kepada National Institute for Environmental Studies, Tsukuba, Japan yang telah bekerjasama dengan Pusat Penelitian Biologi LIPI sebagai penyandang dana dalam kegiatan penelitian ini. Ucapan terima kasih.juga disampaikan kepada Bpk. Herwin Simbolon selaku pimpinan proyek kegiatan penelitian ini dan kepada pimpinan PT Perhutani I yang telah mengijinkan penulis menggunakan area kawasan Wisata Bukit Bangkirai untuk sarana penelitian. Tak lupa ucapan terimakasih juga disampaikan kepada semua fihak yang telah membantu hingga selesainya penelitian dan penulisan naskah ini sampai dapat dipublikasikan.

\section{DAFTAR PUSTAKA}

1. Richards, P.W. 1984. The Ecology of Tropical Forest Bryophytes. In R.M. Schuster (ed.) New manual of Bryology, Nichinan 2: 1233-1266.

2. Longton, R.E. 1992. The Role of Bryophytes and Lichens in terrestrial ecosystems. Dalam Bates, J.W. \& A.M. Farmer (Eds.). Bryophytes and Lichens in a changing environmental. Oxford. 32-76

3. Touw, A. 1978. The Mosses Reported from Borneo. Journ. Hattori Bot. Lab. 44:147-176

4. Conard, H.S. 1982. How to knoe Mosses and Liverworts. Second editions. Wm. C. Brown Company Publishers. Dubuque, Iowa. 302 halaman

5. Eddy, A.1988.A Handbook of Malesian Mosses Volume 1 (Sphagnales to Dicranales). The Natural History Museum. London 204 halaman

6. Eddy, A.1990. A Handbook of Malesian Mosses Volume 2 (Leucobryaceae to Buxbaumiaceae). The natural History Museum. London 256 halaman

7. Eddy, A.1996. A Handbook of Malesian Mosses Volume 3 (Sphlaghnaceae to Leptostomataceae) The Natural History Museum. London. 277 halaman

8. Bartram, E.B.1939. Mosses of the Philippines.In the Philippine Journal of science.68:1-423

9. So, M.L. 1995. Mosses and Liverworts of Hong Kong volume 1. Heavenly People Depot. 162 halaman + i-viii.

10. Ellis, L.T. \& B.C. Tan. 1999. The Moss family Calymperaceae (Musci) in the Philippnes. Dalam Bull. Nat. Hist. Musc. Lond. (Bot.) 29(1): 1-46.

11. Richardson, D.H.S.1981. The Biology of Mosses. Backwell Scientific Publications, Oxford, London, Edinburgh, Boston Melbourne. 220 pp.

12. Yamaguchi,T. 1993. A Revision of the Genus Leucobryaceae (Musci) in Asia. Journal Hattori Bot Lab. 73 : $1-123$

13. Reese, W.D. 1978b. World ranges, implications for patterns of historical dispersal and speciations, and comments on phylogeny of Syrrhopodon (Calymperaceae). Memoirs of the New York Botanical Garden 45: 426-445.

14. Yamaguchi,T., F.I. Windadri, I. Haerida , H. Simbolon, A. Kunimura, H. Miyawaki \& H. Shimizu. 2005. Effects of forest fires on Bryophyte Flora in East Kalimantan, Indonesia. Dalam Phyton 45(4): 561-569. 